
Q francetelecom

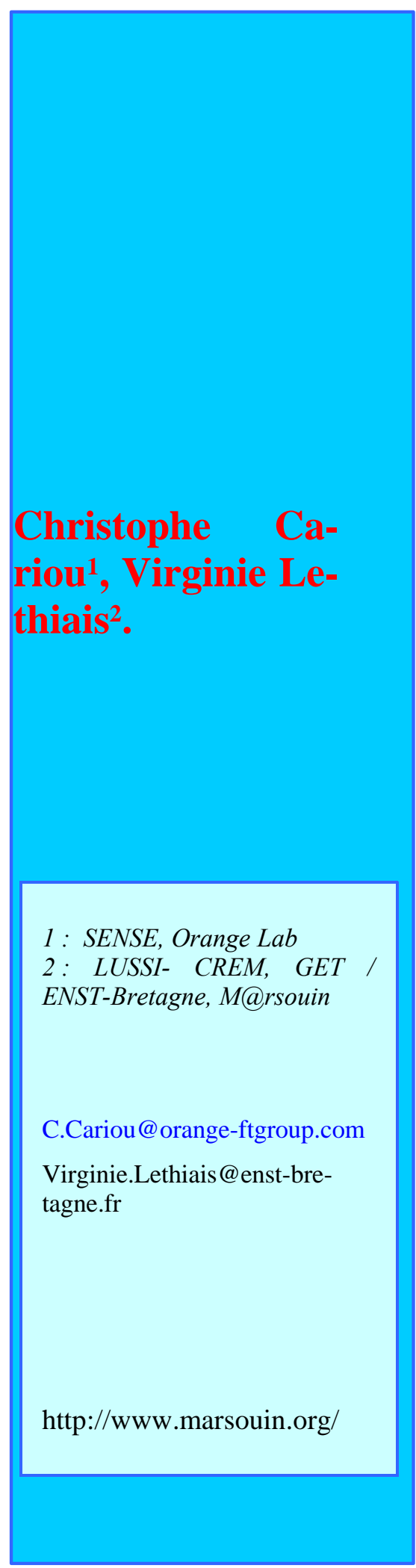

\section{CAHIER DE RECHERCHE.}

Mai 2007 - Numéro 10-2007

\title{
Proximity, technology and mode of diffusion as determinants of know- ledge flows
}

RÉSUMÉ.

Dans cet article, nous étudions les relations de coopération entre les entreprises, comprises en tant que diffusion et partage de connaissances, proximité entre partenaires et mode de diffusion. Nous avons réalisés une étude empirique auprès de 348 entreprises. Les résultats sont en ligne avec ceux trouvés dans la littérature: la distance, les communications virtuelles et le savoir-quoi (know-what) augmente la connaissance codifiée échangée entre les entreprises, alors que les communications "physiques» ont l'effet inverse. De plus, plus les entreprises échangent de savoir-quoi, plus elles échangent aussi des types de connaissance complémentaires (savoir comment, savoir pourquoi); plus la collaboration est inter-régionale, et fondée sur des communications virtuelles, plus la connaissance échangée est codifiée.

Mots Clefs : DIFFusion DES CONNAISSANCES, UTILISATION DES TIC, PROXIMité GÉOGRAPHIQUE, CHANGEMENT TECHNIQUE.

\section{ABSTRACT.}

In this paper, we analyze the cooperative relations of firms, in term of knowledge diffused and shared, proximities between partners, and modes of diffusion. An empirical investigation is undertaken near 348 firms. The results are consistent with the literature: the distance, the virtual communication and the know-what increase the codified knowledge shared among firms, while the real communication have the opposite effect. However, the results do not suggest an opposition between virtual and real communication or between know-what and know-how, but rather a complementarity of these elements. Indeed, the more firms share know-what, the more they share complementary types of knowledge (know-how and know-why), and the more the collaboration is inter-regional and funded on virtual communication, and the more the shared knowledge is codified.

Keywords: KNOWLEDGE DIFFusion, ICT uSE, GEOGRAPHICAL PROXIMITY, TECHNOLOGICAL CHANGE

JEL Classification: O33 - R19 - D83. 


\section{INTRODUCTION.}

The tacit knowledge argument usually used to explain the geographical concentration is unsatisfactory and introduce a restrictive reading of the process: explicit / technology / dispersion versus tacit / face-to-face / concentration.

The French school of proximity dynamics shows that proximity covers a number of dimensions (Torre and Gilly, 2000). Following Boschma (2005), we distinguish the technological and organizational (at the level of firms), the cognitive and relational (at the level of individuals), the institutional and the geographical proximities. These proximities widely moderate the role of geographical proximity for the emergence and the development of knowledge externalities. For example, Breschi and Lissoni (2006) and Singh (2005) find that the relational proximity among inventors is the main channel for the diffusion of an explicit knowledge (patent), and this proximity makes it possible to exceed the other borders.

Several connected questions remain. In a relation between two partners, what is the goal of the relation, what kinds of knowledge are diffused, what are the tools used to communicate? In sum, if the initial and the final knowledge are explicit (in the case of patents), which is really the content of diffused knowledge through the relation among partners?

The distinction introduced with Polanyi (1966) between implicit and explicit knowledge seems to be accepted by almost interested in the economics of knowledge. An ongoing discussion remains in connection with the dramatically development of ICT: how far knowledge can be codified? However, if the issue opposes Cowan et al. (2000) and Johnson et al. (2002), they widely accept the following fact: at any moment of time, most economically useful knowledge is a mix of the both implicit and explicit knowledge.

If the distinction is theoretically interesting, it is practically more difficult. So, this assumption leads us to distinguish two characteristics from the process of knowledge diffusion. On the one hand, Lundwall and Jonhson (1994) distinguish four kinds of knowledge: know-what, knowwhy, know-how and know-who. On the other hand, Jensen and al. (2004) distinguish two modes of diffusion according to the object of relation: codification or interaction.

Moreover, the diffusion channel (face-to-face, ICT or both) depends widely on these assumptions. Like proximity, ICT covers a number of platforms beyond Internet and email: collaborative, organizational, storage platforms, etc. These platforms have not the same usages, according to the kinds and objects of knowledge diffusion and the effective proximities.

The goal of this paper is to test the determinants of the knowledge diffusion between partners. We use the annual regional survey "Firms and ICT" addressed by M@rsouin in 2006, to a representative sample of private Breton firms from 10 to 250 employees. In this survey, in which firms are questioned on their ICT uses, we added two new entries: proximity and knowledge management of firms partnerships. The added value of this survey is to combine the following three types of information, on firms partnerships: proximities, ICT uses and knowledge management.

The qualitative data collected by this survey enable us to test the validity of some hypotheses on the determinants of knowledge diffusion. More precisely, we first test the assumption that knowledge flow between two firms is a combination of codified and non codified knowledge, and a combination of different type of knowledge (know-what, know-how and know-why). A section of the survey allows us to test the impact of geographical, technological and organizational proximities between firms and their partners on the diffusion of knowledge. Finally, another category of questions let us test the link between the kinds of knowledge diffused and the channels of diffusion ( ICT or face-to-face).

For this, we use discrete choice econometric models (multinomial logit). An empirical investigation is undertaken near 348 firms. The results are consistent with the literature: the distance, the virtual communication and the know-what increase the codified knowledge

Môle Armoricain de Recherche sur la Société de l'Information et les Usages d'INternet.

http://www.marsouin.org 
shared among firms, while the real communication have the opposite effect. However, the results do not suggest an opposition between virtual and real communication or between knowwhat and know-how, but rather a complementarity of these elements. Indeed, more the shared knowledge is know-what, more this knowledge is a complement of others types of knowledge (know-how and know-why), and more the collaboration is inter-regional and funded on virtual communication, and more the shared knowledge is codified.

This paper is organized as follow. Section 2 introduces the hypotheses we test in the paper. Section 3 describes the data on firms relationships we have collected and the methodology we use. Section 4 reports and explain the empirical findings. Section 5 discusses some open empirical issues and possible extensions and offers concluding thoughts.

\section{Hypothesis.}

\subsection{Codified vs no codified knowledge.}

The dichotomy between tacit and explicit knowledge gave rise to many hypothesis synthesize by the debate between Cowan et al. (2000) and Johnson et al. (2002). On the one hand, Cowan stresses the necessity and the advantage of knowledge codification. On the other hand, Johnson refuses the possibility of a complete codification, arguing that some knowledge can't be codified without loss. However, they agree on one point: at any moment of time, economically useful knowledge is a mix of the both implicit and explicit knowledge.

The first hypothesis we want to test is the following :

Hypothesis 1. The knowledge shared by firms is a combination of codified and non codified knowledge.

\subsection{Distance vs proximity.}

Torre and Gilly (2000) insist on the different dimensions of proximities and on the interactions between these different dimensions. Boschma
(2005) shows that organizational and institutional proximities favor cognitive and relational proximities and stresses the necessity to understand the link between these dimensions of proximity. Singh (2005) point out the importance of relational proximity (interpersonal network) in determining observed patterns of knowledge diffusion. These theories and results moderate the role of geographical proximity in the diffusion and sharing of knowledge.

In this paper, we want to determine the importance of geographical proximity in the diffusion of knowledge between two cooperative firms. More precisely, we formulate the following hypothesis:

Hypothesis 2. The probability of sharing codified knowledge (relative to non codified knowledge) is greater for firms located in different regions than for firms located in the same region.

\subsection{Technology vs face-to-face.}

Following our first hypothesis, if cooperative firms shared both codified and non codified knowledge, it suggests that, even if they use ICT in their cooperation, this technologies are not sufficient and have to be complete by face-toface.

Hypothesis 3. The mode of communication used by firms to diffuse and share knowledge is a combination of ICT and face-to-face.

However, if ICT are useful to diffuse codified knowledge, it means that there is a link between the codification level of knowledge in a firm and its use of ICT.

Steinmuller (2000) clearly shows the parallel between the use of ICT and the development of codified knowledge inside the firm. The study of Galliano and Roux (2003) suggests that the orientation of the firm toward a greater codification of knowledge (just-in-time, certification...) has a positive impact on the adoption and use of ICT. However, the knowledge codification can respond to an internal or to an external strategy and the use of ICT can also be internal or external. In our paper, we want to test the link bet- 
ween the codification of knowledge and the use of ICT, in an external relationship.

Hypothesis 4. The use of ICT in the firms relationship increases the probability of sharing codified knowledge (relative to non codified knowledge) and the use of face-to-face decreases this probability.

\subsection{Types of knowledge and modes of diffusion.}

The question of the capacity of firm to codify knowledge and then to use ICT to diffuse and share this knowledge is directly link with the question of the kinds of knowledge created, diffused and shared by firms. Lundvall and Johnson (1994) propose the following typology of knowledge: the "know-what" corresponds to generic information, the "know-why" is a more fundamental knowledge, "the know-how" is a specific expertise or competence, and the "know-who" is the knowledge of the individuals who hold particular competences. We want first to determine if this different kinds of knowledge can be identify in the cooperative relationships between firms.

Hypothesis 5. The knowledge shared by firms is a combination of several kinds of knowledge: know-what, know-how, know-why.

Second, we can assume, following Johnson and al. (2004), that some kinds of knowledge can be codified whereas some others cannot. In the typology proposed by Lunwall and Jonhson (1994) the ordered types of knowledge are increasingly difficult to codify. Generic information can be easily clarified, and so corresponds to explicit knowledge that can be codified. Contrary, a specific expertise or competence, held by an individual, cannot be easily clarify; it implies tacit knowledge that cannot be codified.

Hypothesis 6. Some kinds of knowledge are easier to codify.

\section{Data and methodology.}

\subsection{The questionnaire.}

The data we use in this paper come from the annual and regional survey "Firms and ICT" addressed by M@souin in 2006. This annual survey focuses on the ICT use of Bretons firms from 10 to 250 employees, in the sectors of industry (except agriculture), commerce and services. We introduced a section on the questionnaire which was designed to measure the forms and types of share knowledge, the geographical distance and the means of communication used by firms in their collaborations. The administration mode of the questionnaire is double. A part of the questionnaire has been send by mail and then self-managed by firms and another has been carried out by phone. We acquired, consequently, data concerning the most creative collaboration of 348 Brittany firms.

In this paper we focus on 4 questions, and we code them as following:

The exchanges with your partner are based on : 1) documents and files; 2) oral exchanges? The three modality of response are: no, a little and a lot, respectively coded 0,1 and 3 .

In this relation, you share: 1) information related to your activity, 2) fundamental or scientific knowledge, 3) practical experience, expertise and competence? The proposed response are no, a little and a lot respectively coded 0,1 and 3 .

Where is located your partner? The proposed response are within the same activity zone, the same local level, the same regional level, the same national level or the same international level.

The share of knowledge is based on: 1) ICT communication , 2) face-to-face discussion? For each mean, the proposed modalities are : very major use, major use, minor use, no use, coded respectively $3,2,1$ and 0 . 


\subsection{The dependent variable.}

The dependent variable is the codified character of shared knowledge. In others words, we focus on the importance of written documentation. However, it seems impossible to analysis written versus oral knowledge independently. Indeed, using a Khi2 test, we reject the joint hypothesis that the written documentation and oral exchange are independent with an error of three per thousand. Consequently, the hypothesis 1 is valid and we consider the knowledge shared by firms as a combination of codified and non codified knowledge.

Then, we construct an indicator of codified knowledge as the importance of the written documentation balanced by the relative importance. In other words, we use for weighted codified knowledge the following measure:

$$
\text { Codified knowledge }=\frac{\text { written }}{\text { written }+ \text { oral }} \text {. written, }
$$

where the variable written, respectively oral, equals 0,1 or 3 if the firm uses no, a little, or a lot of documents and files, respectively oral exchanges, in its cooperative relation.

This is the dependent variable with exclusive multimodalities. Then, the logit estimation indicates the variables which increase or decrease the probability of sharing more and more codified knowledge.

\subsection{Definition of variables and mea- sures.}

The explanatory variables are represented by the three other questions: location of the patners, means of communication and types of knowledge. We test these variables in two logics: in an independent manner and in a dependent manner, i.e. by building relative measures, that we call mode of communication and mode of diffusion.

A distinction is made between the means of communication and the modes of communication. The mean considers the virtual and real communication as independent whereas the mode considers them as dependent. Consequently, the mean measures the importance of ICT and face-to-face within the framework of collaboration; the modalities are $0,1,2$ or 3 for respectively no use, minor use, major use or very major use. The mode considers the prevalence of a mean of communication on the other. Three different modes are possible:

- the virtual mode is a collaboration principally based on the ICT communication relatively to the face-to-face discussion: ICT are more used than face-to-face;

- the real mode is a collaboration principally based on the face-to-face discussion relatively to the ICT communication: faceto-face is more used than ICT;

- the dual mode is a collaboration founded on an equivalent use of the two means of communication: ICT and face-to-face are used in an equivalent way.

For each variable, the value is the sum of the values of ICT and face-to-face use.

The same distinction is made between the types of knowledge and the modes of diffusion. In the questionnaire, we consider three types of knowledge that can be shared by firms : the knowwhat, which corresponds to the information related to the activity of the firm, the know-why, which fits to fundamental or scientific knowledge and the know-how, which corresponds to practical experience, expertise and competence. Given this three types of knowledge, we construct seven possible modes of diffusion:

- three exclusive modes based on an only one type of knowledge;

- three dual modes, based on an equivalent diffusion of two of the three types of knowledge;

- a triple mode, based on an equivalent diffusion of the three types of knowledge.

For each variable corresponding to a the type of knowledge, we have three modalities : 0 for "no", 1 for "a little" and 3 for "a lot". If $\mathrm{m}_{\mathrm{i}}$ is the modality of variable $i$, the mode of diffusion is defined is the following way: 
- if $m_{i}>m_{j}, \forall j \neq i$, then the mode is $\mathrm{i}$;

- if $m_{i}=m_{j} \neq m_{k}, \forall(i, j) \neq k$ then the mode is $\mathrm{i}$ and $\mathrm{j}$ (dual mode);

- if $m_{i}=m_{j}=m_{k}, \forall i \neq j \neq k$ then the mode is the triple mode.

The value of each variable describing the modes of diffusion is the sum of the values of the associated types of knowledge:

$$
\text { mode_value }=\sum_{i=1}^{k} m_{i}
$$

Table 1 reports descriptive statitics and correlations. Except the variable "within the same region", the other variables are coded from 0 to 3 , with an average value of 1.5 .

Tableau 1. Descriptive statistics and correlations

\begin{tabular}{|l|l|l|l|l|l|l|l|l|l|}
\hline & & Mean & $\begin{array}{l}\text { Std } \\
\text { Dev }\end{array}$ & 1. & 2. & 3. & 4. & 5. & 6. \\
\hline 1. & $\begin{array}{l}\text { Codified } \\
\text { flows }\end{array}$ & 1.50 & 0.90 & & & & & & \\
\hline 2. & $\begin{array}{l}\text { Within } \\
\text { region }\end{array}$ & 0.39 & 0.49 & -0.21 & & & & & \\
\hline 3. & ICT uses & 2.10 & 1.03 & 0.28 & -0.15 & & & & \\
\hline 4. & $\begin{array}{l}\text { Face-to- } \\
\text { face }\end{array}$ & 2.23 & 0.86 & -0.21 & -0.02 & -0.07 & & & \\
\hline 5. & $\begin{array}{l}\text { Know- } \\
\text { what }\end{array}$ & 2.38 & 1.06 & 0.29 & -0.18 & 0.14 & 0.04 & & \\
\hline 6. & $\begin{array}{l}\text { Know- } \\
\text { how }\end{array}$ & 1.57 & 1.36 & 0.07 & 0.01 & 0.20 & 0.12 & 0.17 & \\
\hline 7. & $\begin{array}{l}\text { Know- } \\
\text { why }\end{array}$ & 0.73 & 1.17 & 0.03 & -0.00 & 0.14 & 0.04 & 0.20 & 0.4 \\
5
\end{tabular}

\subsection{The multinomial logit model.}

This paper presents the preliminary results of the logit estimation in Table 2 to 5. Tables give the coefficients and standard errors are given in parentheses; asterisks indicate the degree of significance, one for $10 \%$, two for $5 \%$ and three for $1 \%$. A positive sign means that an increase in the value of the variable increases the probability of codified knowledge flows, and inversely for a negative sign.

The models presented are all significant for tests of the proportional odds assumption and the joint significance of the explanatory variables. All the models are estimated with a controlled variable to distinguish the administration mode of questionnaire (self-managed by firms or carried out by phone).

The models are controlled by the sector of activity of the firms. We do not indicate the estimates for these variables because we concentrate the analysis only on three categories of variables. In this version of the paper, we distinguish three sectors of activity: industry, commerce and service, and we want complete our analysis later with a more precise division into sectors.

\section{Results.}

\subsection{The choice of regional frontier.}

Table 2 reports econometric analysis to test the hypothesis 2 , i.e. the impact of distance on the probability of sharing more codified knowledge, and justifies our choice to consider the regional frontier.

Tableau 2. Does Distance Help to Explain Probability of Sharing more Codified Knowledge.

\begin{tabular}{|l|l|l|l|l|}
\hline & \multicolumn{1}{|c|}{$(1)$} & \multicolumn{1}{|c|}{$(2)$} & \multicolumn{1}{|c|}{$(3)$} & $(4)$ \\
\hline Activity zone & 0.09 & $-1.0177^{* *}$ & ref. & \\
\hline Local level & 0.14 & $-0.8195^{* *}$ & 0.1981 & \\
\hline Regional level & 0.16 & $-0.6921^{*}$ & 0.3256 & \\
\hline National level & 0.43 & -0.0027 & $1.0149 * *$ & \\
\hline International level & 0.18 & ref. & $1.0177 * *$ & \\
\hline & & & & \\
\hline Within the same region & 0.39 & & & $-0.8046^{* * * *}$ \\
\hline
\end{tabular}

Column (1) reports the frequencies of answers to the question : "where is located your most creative partner?" $39 \%$ of the firms answers that its most creative collaboration is co-located within the same region. In other words, the majority of the most creative collaborations are interregional and a great part is located within the national frontier $(43 \%)$. And there are more international partners $(18 \%)$ than regional (16\%), local (14\%) and more closed (9\%) partners. Such result seems consistent with the literature relative to the less influence of distance: the codified knowledge is not constraint by the distance. 
the same zone, in local or in regional frontiers has a negative and significant impact on the probability of sharing more codified knowledge going in the direction of negative influence of geographical proximity. The estimate for national frontiers is not significant. When we change the reference variable, the result is in favor of geographical distance in an increasing way, and the estimates for the same activity zone, the local level and the regional level are not significant.

To summarize, the probability of sharing more and more codified knowledge is a increasing function of geographical distance. In our empirical investigation, considering a binary variable (within the same region) or five binary variables (from activity zone to international level) do not contribute to give more information. Consequently, we use the regional frontier to distinguish the effect of co-location of partners. That what we do in the model presented in column (4), which shows that the co-located collaborations tend to use less codified knowledge flows.

\subsection{The influence of virtual and real communications.}

Table 3 reports econometric analysis to test the hypotheses 3 and 4, i.e. the impact of means and modes of communication on codified flows. Colocation is introduced in the same model.

Tableau 3. Effect of Distance and Communication on The Probability of Sharing Codified Knowledge.

\begin{tabular}{|l|c|c|c|c|}
\hline & $(1)$ & $(2)$ & $(3)$ & $(4)$ \\
\hline Within the same region & $-0.6461^{* * *}$ & & $0.6063^{* * *}$ & \\
\hline ICT uses & $0.4975^{* * *}$ & & & \\
\hline -intra-region & & $0.5134^{* * *}$ & & \\
\hline -inter-region & & $0.4615^{* * *}$ & & \\
\hline Face-to-face uses & $-0.4217 * * *$ & & & \\
\hline -intra-region & & $-0.6174^{* * *}$ & & \\
\hline -inter-region & & $-0.3212^{* *}$ & & \\
\hline ICT mode & & & $0.1631^{*}$ & \\
\hline -intra-region & & & & 0.0757 \\
\hline -inter-region & & & & $0.1853^{* *}$ \\
\hline Face-to-face mode & & & 0.1416 & \\
\hline -intra-region & & & & $-0.2631^{*}$ \\
\hline -inter-region & & & & $*$ \\
\hline ICT equal Face-to-face & & & 0.0630 & \\
\hline -intra-region & & & & -0.0006 \\
\hline
\end{tabular}

Môle Armoricain de Recherche sur la Société de l'Information et les Usages d'INternet.

http://www.marsouin.org

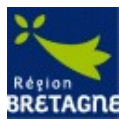
negative and significant impact of the co-located collaborations on the probability of codified knowledge flows, even while taking into account the means of communication. In others words, the geographical proximity hinders the diffusion of codified knowledge. Comparing the table 3 and table 4 , the value is decreasing from -0.80 to -0.65 , which means that considering the means of communication reduces the effect of co-location.

Column (1) tests also hypothesis 3 and shows a significant effect for virtual and real communication but with opposite effects. Interestingly, the magnitudes are very closed. In other words, if a collaboration is based on intense face-toface discussion and ICT communication, the influence on probability of sharing more codified knowledge is closed to zero. This suggests a possible complement more than a substitute between the two means of communication.

As Column (2) shows, the impact of the face-toface is not the same according to the location of the partners (intra- or inter-regional), even if the two are negative and significant. The face-toface discussion decreases the probability of sharing codified knowledge more if the collaboration is intra-regional: the effect is twice greater that if the partner is distant. This result is consistent with the literature.

The result is not the same for the virtual communication, and not consistent with the literature. Indeed, the virtual communication increases more the probability of sharing more codified knowledge between two co-located collaborators than between two distant partners. One possible explanation is that the virtual and the real communication are not substitutes but complements, which appears clearly in the interpretation of columns (3) and (4).

The joint hypothesis that the means of communications are independent is rejected with an error of 1 per thousand, with a Khi2 test. Column (3) and (4) reports the estimates of the modes of communication i.e. the privileged use of one of means of communications. Column (3) 
finds a significant estimates only for the mode of virtual communication, and eliminates the mode of real communication (negative sign however), but equally the mode where real and virtual communication have the same "importance" in the collaboration. To summarize, in a collaboration which uses principally face-to-face discussion or the two means of communications an increase in the volume of communication does not influence the probability of sharing more and more codified knowledge.

Column (4) disaggregate the mode of communication between intra- and inter-regional collaborations, and suggests a more complex relationship between codification and communication. Indeed, the effect of virtual mode is positive and significant only in the case of an inter-regional use, and the effect of real mode is negative and significant only in the case of an intra-regional use. This confirms the explanation of the complementarity of the two means of communications. An finally, the two means of communication influence the probability of codified knowledge flows in a almost perfect opposition, as the global effect and the no-effect of the dual mode shows.

\subsection{Types of knowledge and modes of diffusion.}

Table 4 reports the results of the econometric analysis testing hypotheses 5 and 6, i.e. the impact of types of knowledge on probability of sharing more codified knowledge.

\section{Table 4}

Tableau 4. Do Types of Knowledge and Modes of Diffusion Explain The Probability of Sharing more Codified Knowledge?

\begin{tabular}{|c|c|c|}
\hline & $(1)$ & $(2)$ \\
\hline \multicolumn{3}{|l|}{ Types } \\
\hline \multicolumn{3}{|c|}{ Know-what $0.5743 * * *$} \\
\hline \multicolumn{3}{|c|}{ Know-how 0.0435} \\
\hline \multicolumn{3}{|c|}{ Know-why -0.0142} \\
\hline \multicolumn{3}{|l|}{ Modes } \\
\hline Know-what & & $0.5846 * * *$ \\
\hline Know-how & & $0.3343 * * *$ \\
\hline Know-why & & ref. \\
\hline $\begin{array}{r}\text { Know-what equal } \\
\text { Know-how } \\
\end{array}$ & & $0.3082 * * *$ \\
\hline Know-how equal & & 0.1506 \\
\hline
\end{tabular}

\begin{tabular}{|r|l|} 
Know-why & \\
\hline Know-why equal & 0.1631 \\
Know-what & \\
\hline Triple mode & $0.2225^{* * *}$ \\
\hline
\end{tabular}

Column (1) finds results consistent with the literature. The positive and significant estimates of know-what, the type of knowledge more close of information. The know-how has no effect, whereas the literature suggests a negative impact, as this kind of knowledge needs face-toface to be shared. The impact of know-why is not significant, this more fondamental knowledge being not easily to share in a codified manner, and being used more often within firms than between firms.

The joint hypothesis that the types of knowledge are independent is rejected with an error of 1 per thousand, with a Khi2 test. We focus on the modes of diffusion and not only of the types of diffused knowledge. Column (2) finds that the positive and significant impact of know-what on the probability of sharing more codified knowledge is higher than in the model (1). Moreover, when the know-what is mixed with the knowhow or with the know-how and the know-why, the impact on our probability becomes important of the codified knowledge flows. Consequently, theses results suggest the importance of know-what in the different modes of innovation, and particularly the great complementarity between know-what and know-how.

Interestingly, the impact of know-how is not the same in the two columns. In column (1) it is not significant whereas in column (2) it is significant and positive. It means that, when the collaboration is based only on "know how", the impact of more exchange on the probability of using more codified knowledge is null. Inversely, when the "know-how" is the main type of knowledge but combined with other kinds of knowledge, a greater volume of exchange increases the probability of using more codified knowledge. 


\subsection{Distance, communication and types of knowledge.}

Table 5 reports the impact of types of knowledge combined with the distance and the means of communication.

Tableau 5. Distance, means of communication and types of knowledge

\begin{tabular}{|c|c|c|c|c|}
\hline & (1) & (2) & (3) & (4) \\
\hline \multicolumn{5}{|c|}{$\begin{array}{l}\text { Within the same-0.6427*** } \\
\text { region }\end{array}$} \\
\hline \begin{tabular}{|l|l|}
$\mathrm{ICT}$ \\
\end{tabular} & & & $0.4393 * * *$ & \\
\hline -intra-region & & & & $0.4175^{* *}$ \\
\hline -inter-region & & & & $0.3590 * * *$ \\
\hline Face-to-face & & & $-0.4828 * * *$ & \\
\hline \begin{tabular}{|c|}
-intra-region \\
\end{tabular} & & & & $-0.7400 * * *$ \\
\hline -inter-region & & & & $-0.4001 * * *$ \\
\hline Know-what & $0.5240 * * *$ & & $0.5137 * * *$ & \\
\hline \begin{tabular}{|c|}
-intra-region \\
\end{tabular} & & $0.2752 * *$ & & $0.3722 * *$ \\
\hline -inter-region & & $0.7004 * * *$ & & \\
\hline Know-how & 0.0317 & & -0.0485 & \\
\hline \begin{tabular}{|c|}
-intra-region \\
\end{tabular} & & 0.2040 & & $0.3203 * *$ \\
\hline -inter-region & & -0.1217 & & -0.1246 \\
\hline Know-why & -0.0026 & & 0.0626 & \\
\hline \begin{tabular}{|c|}
-intra-region \\
\end{tabular} & & -0.1465 & & -0.1819 \\
\hline -inter-region & & 0.1139 & & 0.0677 \\
\hline
\end{tabular}

Column (2) finds that the know-what has a greater influence between inter-regional collaborators than intra-regional collaborators. This is consistent with the literature and confirms the possibility of sharing this type of knowledge easily between geographical frontiers.

Column (3) suggests that the more the relationship is located within the same region and funded on face-to-face, the less the exhange is (in probability) focused on codified knowledge. Moreover, the more the relationship is funded on ICT uses and concerned the know-what, the more the exchange is (in probability) focused on codified knowledge. And, the impact of these two groups is opposed in magnitude.

Column (4) disaggregates the variables between intra-regional and inter-regional relations. The face-to-face between collaborators decreases the exchange of codified knowledge, and the impact is higher when these meetings take place within the same region. Finally, the know-what has a greater impact between distant collaborators that between regional partners.

\section{Conclusion.}

To conclude, most of our results are consistent with the literature: the distance, the virtual communication and the know-what increase the codified knowledge shared among firms, while the real communication have the opposite effect. However, results do not suggest an opposition between virtual and real communication or between know-what and know-how, but rather a complementarity of these elements. Indeed, the more the shared knowledge is know-what, the more this knowledge is a complement of others types of knowledge (know-how and know-why), and the more the collaboration is inter-regional and funded on virtual communication, and the more the shared knowledge is codified.

This presentation reports only the preliminary results and need to be complete in three directions:

- the specialization on sectors of activity of firms: here, we have used an usual industrycommerce-services classification; however, number of studies underline the influence of the classification; for example, in our investigation, the know-why is never significant; we can assume that it is specific to a technological sector;

- the non codified knowledge flows: it would be interesting to complete the analysis with the estimation of the "symmetric" probability, that is the probability of using more non codified knowledge. We find that the explanatory variables are not the strict opposition of these presented in this paper;

- other questions in the questionnaire can contribute to refine the results; for example, the means of communications in terms of quality can be complete by the frequency of used of the different means of communication.

\section{References.}

Boschma R., 2005, "Proximity and innovation: a critical assessment”, Regional Studies 1, p61-74. 
Breschi S., Lissoni F., 2006, "Mobility and social networks: localised knowledge spillovers revisited", Annales d'Economie et Statistique, forthcoming.

Cowan R., David P.A., Foray D., 2000, "The explicit economics of knowledge codification and tacitness", Industrial and Corporate Change 9, p211-253.

Galliano D., Roux P., 2003, "Espaces, organisations et TIC : les enseignements d'une comparaison intersectorielle", Géographie, Economie et Société 4.

Jensen M.B., Johnson B., Lorenz N. and Lundvall B.A., 2004, "Codification and modes of innovation", Paper presented at the DRUID Summer Conference, Elsinore, Denmark, June.

Johnson B., Lorenz E., Lundvall B.A., 2002, "Why all this fuss about codified and tacit knowledge?", Industrial and Corporate Change 2, p245-262.

Lundvall B.A., Johnson B., 1994, "The learning economy", Journal of Industry Studies 2, p23-42.

Polanyi M., 1966, The tacit dimension, Doubleday, NewYork.

Singh J., 2005, "Collaborative networks as determinants of knowledge diffusion patterns", Management Science 5, p756-770.

Steinmueller W.E., 2000, "Will new information and communication technologies improve the codification of knowledge?", Industrial and Corporate Change 2, p361-376.

Torre A. and Gilly J.P., 2000, "On the analytical dimension of proximity dynamics", Regional Studies 34, p169-180.

\section{LES BULLETINS RÉCENTS.}

\section{Année 2007.}

9-2007. Cariou C. Les relations créatives des entreprises entre proximités et technologies : un état de l'art.

8-2007. Colombier N., Martin L., Pénard T. Les salariés sont-ils réellement satisfaits des TIC ?

7-2007. Tiemtoré W. Z. Les TIC dans l'éducation en Afrique sub-saharienne: espoir fondé de développement ou émergence d'une nouvelle utopie ?
6-2007. Plantard P. TICE et nouvelles formations professionnelles à l'université : approches anthropologiques.

5-2007. Bouder C., Charlier J.-M., Leray Y., Mével O. Enjeux et perspectives de la logistique des retours appliquée à la grande distribution : l'exemple des D3E.

4-2007. Le Goff M., Lethiais V. TIC, besoins de coordination et d'information et proximité géographique : une analyse sur des données bretonnes.

3-2007. Trémenbert J., Jullien N. L'évaluation du rapport des TPE de l'artisanat aux TIC. Le cas de la Bretagne.

2-2007. Le Borgne et al. Évaluation des usages du Dossier Patient Partagé au sein d'un réseau d'addictions. Analyse sociologique versus analyse des « logs files ». Application au réseau ADDICA, Champagne-Ardennes.

1-2007. Trellu H. Création des réseaux de santé et usages du dossier médical partagé.

\section{Année 2006.}

13-2006. Jullien N., Trémenbert J. Les PME bretonnes : leur équipement en technologies numériques, leurs usages et leurs attentes.

12-2006. Thierry D. Modalités de circulation de 1'information sur un territoire régional.

11-2006. Pénard T., Suire R. Le rôle des Interactions Sociales dans les modèles économiques de l'Internet.

10-2006. Petr C., Guéguen N. Beginner Research on Tourism and the Tourist: Beware of Words and Caricatures!

9-2006. Dang Nguyen G., Mével O. Nouvelle et et ancienne économie : vers une intégration réussie ?

8-2006. Jullien N., Zimmermann J.-B. Free/Libre/Open Source Software (FLOSS): lessons for intellectual property rights management in a knowledge-based economy.

7-2006. Demazière D., Horn F., Jullien N. How free software developers work. The mobilization of "distant communities".

6-2006. Pénard T., Poussing N. Usage d'Internet et capital social. 
Responsables de l'édition : Godefroy Dang Nguyen, Nicolas Jullien.

Contact : Nicolas Jullien

M@rsouin

GET - ENST Bretagne

CS 83818, 29238 Brest CEDEX 3

Marsouin@infini.fr

(0)229001245 